\title{
An Intrauterine Device Detected in Ovary during Cesarean Section: A Case Report
}

\author{
Fazil Avci, Hakan Kiran, Murat Bakacak*, Gürkan Kiran, Salih Serin
}

\begin{abstract}
The copper T Intrauterine Device is a common method of contraception used throughout the world. Intrauterine or ectopic pregnancies may be caused by complications with an IUD. The aim of this study was to present an ongoing term pregnancy with a copper T extrauterine device localized in the ovary. Assessment of the clinical features of a term pregnancy complicated by an IUD. A 32-year-old female was fitted with a copper T IUD in October 2009. She was hospitalized due to a term pregnancy with recurrent cesarean history and had the IUD where was not known. Laboratory values and fetal biometry were normal. A viable normal 3750 g male infant with 8/9 Apgar score was delivered by cesarean section without any abnormalities. In pelvic exploration, the IUD was localized in the left ovary and removed. Mother and infant were discharged without any complications after 24 hours. Counselling should be provided about the potential risks of an ongoing pregnancy for all patients with the complication of copper T in place. It is rare to have a successful delivery of a term normal pregnancy complicated with an IUD.
\end{abstract}

Keywords: Intrauterine device, Ovary, Pregnancy

\section{Introduction}

The Intrauterine Device (IUD) is the second most common contraceptive method used throughout the world after sterilization. Usage is estimated at $15 \%$ of reproductive women worldwide (160 million women) (1). The Copper $(\mathrm{Cu}) \mathrm{T} 380 \mathrm{~A}$, which is one of the latest generation copper IUDs, provides significant contraception (99\%) for 10 years with a very low expulsion rate (2). Recent studies have shown show that after IUD insertion, rates of ectopic and intrauterine pregnancies have been reported at 62.5 and $37.5 \%$, respectively. In a study of 15 intrauterine pregnancies, 5 were terminated, 8 miscarried and only 2 reached term (3). In this study a case of an ongoing term pregnancy with a Copper $\mathrm{T}$ extrauterine device localized in the ovary is presented.

\section{Case Presentation}

A 32-year-old para 3 female was fitted with a copper T IUD in October 2009. The patient had no history of medical disease. She was hospitalized due to a term pregnancy with recurrent cesarean history and with the consideration that an IUD was still in place. The laboratory values were normal, the non-stress test was reactive and fetal biometry was normal. Cesarean section was performed under spinal anaesthesia, and a viable normal male infant with $8 / 9$ Apgar score and $3750 \mathrm{~g}$ in weight was delivered without any abnormality. The IUD was not observed in the uterine cavity. There was no finding of uterine perforation. In the pelvic exploration, the copper T IUD was seen in the left ovary and removed (Figures 1 and 2).

Bilateral fallopian tubes and right ovary measuring $2-3 \mathrm{~cm}$ in diameter were observed to be normal. A copper T IUD was seen in the left ovary, which was $3-4 \mathrm{~cm}$ in diameter, edematous and with increased vascularity. After releasing the adhesions between the fallopian tube and ovary within 20 minutes, the IUD was dissected bluntly into the ovary and removed. However, a slight abscess measuring 1-2 cm in diameter, yellow to green-brown in colour was observed in the space from which the IUD had been removed. This was drained and irrigated with saline. There were no procedure-related complications. Cefazolin sodium $2 \mathrm{~g} /$ day intravenously and Ornidazole $1 \mathrm{~g}$ /day were administered postoperatively. The follow-up of patient was not remarkable and mother and neonate were discharged without any complications after 24 hours.

\section{Discussion}

Contraception prevents unwanted pregnancies by affecting ovulation, fertilization and implantation. The usage of contraception by $63 \%$ of reproductive women worldwide was reported (4). After pregnancy and other contraindications have been excluded, the IUD can be inserted safely at any time during the menstrual cycle (5). During IUD insertion, there may be complications such as displacement, expulsion, pelvic inflammatory disease, perforation and bleeding (6). Rates of failure rate for this type of IUD have been reported at 0.3 to $2.3 \%$ (7). Sperm motility has been reported to be inhibited due to increased concentrations of copper in the cervical mucus caused by a copper IUD (8). The presence of a copper IUD has been seen to result in a higher inflammatory response of the endometrium, which suggests that copper IUDs may have a stronger 


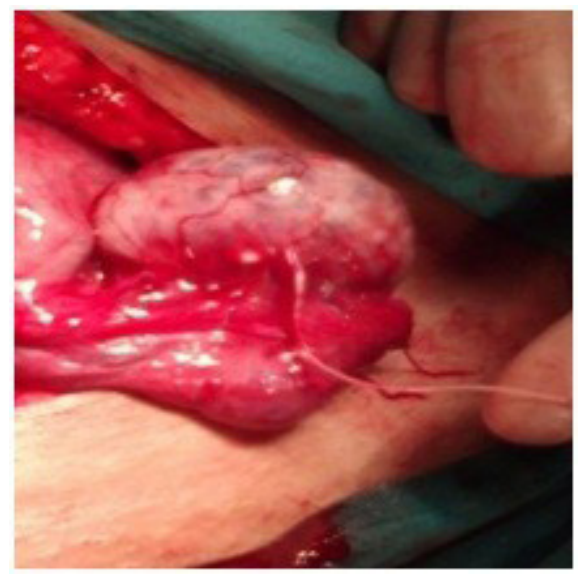

Figure 1. Localization of copper T IUD in the left ovary.

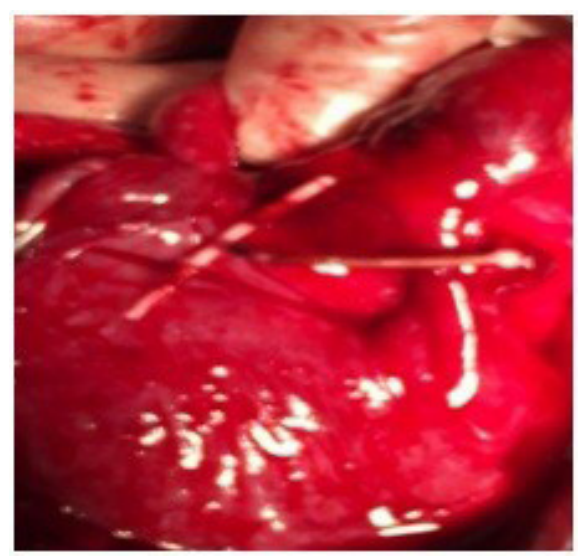

Figure 2. The left ovary after removal of the IUD.

spermicidal effect on the endometrial area (9). Also a study has shown that copper ions inhibit sperm motility but not necessarily the capacity for fertilisation (10).

While clinically recognized ectopic pregnancies with an inert or copper IUD in place have been observed at 3-4\%, this rate is approximately $25 \%$ with the use of levonorgestrel and progesterone (11). Adverse obstetric outcomes such as preterm delivery, low birth weight and chorioamnionitis have been reported in women with IUD (12). While possible contraindications for use of IUD are active pelvic inflammatory disease, serious cervicitis, undiagnosed genital bleedings, pregnancy, uterine anomaly and suspected malignancy, some studies have also been studied in women who had the device removed in early pregnancy $(13,14)$.

No differences were detected in regard to congenital malformations among women with an IUD, those who had it removed, and those with no IUD (15). Recent evidence has demonstrated a rise in the incidence of cleft lip in pregnancies with IUDs, although the report was from a small series of 10 pregnancies with devices (16). A strong factor affecting the course of pregnancy has been reported to be dislocation of the device, which is often encountered in the first year of IUD placement (17).

\section{Conclusion}

This case report demonstrates that a pregnancy test should be offered to all patients with an IUD and counselling on the potential risks of continuing the pregnancy. All patients with an IUD should be informed about the potential disadvantages of the IUD, which may be the death of an embryo or continuation of normal development in the "all or nothing period" in the preimplantation period. In our case, when we did not know that another physician had inserted the IUD, perhaps it was thought that it could have dislocated or perforated the uterus during the insertion process. Therefore, for early diagnosis of these complications, regular examinations are of great importance for women fitted with an IUD. It is rare for a normal term delivery of a pregnancy complicated by an IUD.

\section{Ethical issues}

An informed consent was obtained from the patient for publication of this case report and the accompanying images. Approval for the study was granted by the Local Ethics Committee of Kahramanmaras Sutcu Imam University School of Medicine/Turkey.

\section{Conflict of interests}

The authors declare no conflict of interests related to this manuscript.

\section{Acknowledgments}

We would like to thank all our colleagues who helped in this study.

\section{References}

1. World Health Organization. The intrauterine device, worth singing about. Progress in Reproductive Health Research 2002;60:1-8.

2. Sinei SK, Schulz KF, Lamptey PR, Grimes DA, Mati JK, Rosenthal SM, et al. Preventing IUCD-related pelvic infection: the efficacy of prophylactic doxycycline at insertion. Br J Obstet Gynaecol 1990;97(5):412-9.

3. Backman T, Rauramo I, Huhtala S, Koskenvuo M. Pregnancy during the use of levonorgestrel intrauterine system. Am J Obstet Gynecol 2004;190(1):50-4.

4. Amy JJ, Tripathi V. Contraception for women: an evidence based overview. BMJ 2009; 339:b2895.

5. White MK, Ory HW, Rooks JB, Rochat RW. Intrauterine device termination rates and the menstrual cycle day of insertion. Obstet Gynecol 1980;55(2):220-4.

6. Olatinwo AW, Anate M, Balogun OR, Alao MO. Intrauterine contraceptive device: socio-demographic characteristics of acceptors, acceptability and effectiveness in a teaching hospital in Nigeria. Niger J Med 2001;10(1):14-7.

7. de Araujo FF, Barbieri M, Guazzelli CA, Lindsey PC. The T 380A intrauterine device: a retrospective 5-year evaluation. Contraception 2008;78(6):474-8.

8. Hagenfeldt K. Intrauterine contraception with 
the copper-T device: effect on trace elements in the endometrium, cervical mucus and plasma. Contraception 1972;6(1):37-54.

9. Li P, Zhong Y, Jiang X, Wang C, Zuo Z, Sha A. Seminal plasma metals concentration with respect to semen quality. Biol Trace Elem Res 2012;148(1):1-6.

10. Mishell DR Jr. Intrauterine devices: mechanisms of action, safety, and efficacy. Contraception 1998;58(3Suppl):45S-53S.

11. Xiong X, Buekens P, Wollast E. IUD use and the risk of ectopic pregnancy: a meta-analysis of case-control studies. Contraception 1995;52(1):23-34.

12. Simpson JL. Do contraceptive methods pose fetal risks? Res Front Fertil Regul 1985;3(6):1-11.

13. Grimes DA, Gallo MF, Grigorieva V, Nanda K, Schulz KF. Fertility awareness-based methods for contraception. Cochrane Database Syst Rev 2004;(4):CD004860.
14. Pill, IUD users run no increased risk of ectopics, malformation, miscarriage in planned pregnancies. Fam Plann Perspect 1980;12(3):156-7.

15. Fulcheri E, di Capua E, Ragni N. Pregnancy despite IUD: adverse effects on pregnancy evolution and fetus. Contraception 2003;68(1):35-8.

16. Dunn JS Jr, Zerbe MJ, Bloomquist JL, Ellerkman RM, Bent AE. Ectopic IUD complicating pregnancy. A case report. J Reprod Med 2002;47(1):57-9.

17. Division of Reproductive Health, National Center for Chronic Disease Prevention and Health Promotion, Centers for Disease Control and Prevention. U.S. Selected Practice Recommendations for Contraceptive Use, 2013: adapted from the World Health Organization selected practice recommendations for contraceptive use, 2 nd edition. MMWR Recomm Rep 2013;62(RR-05):1-60.

Copyright ( 2014 The Author(s); This is an open-access article distributed under the terms of the Creative Commons Attribution License (http://creativecommons.org/licenses/by/4.0), which permits unrestricted use, distribution, and reproduction in any medium, provided the original work is properly cited. 